\title{
Spectacular Cities of Our Time
}

\section{Editorial for a Special Issue, "Spectacle Cities," for Geoforum}

Note: This editorial has been published in Geoforum (article in press, 2015) http://www.sciencedirect.com/science/article/pii/S0016718515001657

Please cite this article in press as: Chu, C.L., Sanyal, R. Spectacular cities of our time. Geoforum (2015), http://dx.doi.org/10.1016/j.geoforum.2015.06.016

\section{Cecilia L. Chu}

Department of Urban Planning and Design

8/F Knowles Building

The University of Hong Kong

Pokfulam, Hong Kong

Email: clchu@hku.hk

\author{
Romola Sanyal \\ Department of Geography \& Environment \\ The London School of Economics and \\ Political Science \\ Houghton Street, London WC2A 2AE \\ The United Kingdom \\ Email: r.sanyal@1se.ac.uk
}

In 1967, Guy Debord proclaimed that the spectacle has become the central organizing principle in modern societies. In his thesis the commodity, in being separated from the activity by which it is produced, is no longer something that enters into the sphere of experience in fulfilling particular needs or desires, but has itself become the constituent of the world of experience, reorganizing the urban milieu and everyday discourse (Debord, 1967; Brenkman, 1979). To many contemporary critics, the spectacle has indeed triumphed in recent decades with the advent of the 'experience economy' amidst neoliberal capitalist globalization (Best and Kellner, 1998; Foster, 2008; Gotham and Krier, 2008; Krupar and Al, 2012 ;). In tandem with accelerating commodification of the built environment is the rapid expansion of the scope of 'the spectacular.' No longer confined to familiar iconic architecture and celebratory built forms, it now encompasses a widening network of 'other' spaces ranging from sites of dissonance and conflicts to types of invented heritage. Increasingly, cities around the world are driven to rebrand themselves by tapping into their cultural and experiential potentials, promulgating novel use of visual symbolisms and creation of affective 'atmospheres' that aim to establish emotional connections between consumers and the environment (Klingmann, 2007; Krupar and Al, 2012; Lee, this issue). While these phenomena suggest the arrival of a new stage of 'spectacular urbanism' with new forms of seduction and domination, these sites and sights also provide impetus for alternative practices, with social actors seeking to transform the meanings of urban space and conjure imaginaries of the city that may or may not align with dominant neoliberal urban agendas. The creative rigor of these 'counter-practices' has led to renewed interest in the work of Debord and the Situationist International (SI) (1957-1972), an organization of avant-garde artists and 
intellectuals whose goal was to overturn established cultural and political practices and 'do harm to spectacular society' (Debord, 1967; Gotham and Krier, 2008). ${ }^{1}$ Although SI's work remains marginalized in the academia, it has long been an inspiration for subversive political acts seeking to unsettle the hegemonic discourses of consumer capitalism (Barnard, 2004; Pinder, 2000, p.360, Woodworth, this issue). ${ }^{2}$

There is certainly no lack of writing on the spectacle since Debord published his thesis nearly half a century ago. As noted by Jonathan Crary, the term is so overused that it has become a stock phrase in a wide range of critical and not so-critical discourses (Crary, 1989, p.96; Pinder, p.361). One troubling aspect, to refer to W.J.T. Mitchell, is that the concept of the spectacle is too powerful and all-explanatory, and it seems to have taken on a life of its own with the "magic shaping power" of capital (Mitchell, 2008. p.577). Its association with a seemingly single totality of an image-saturated world in which people are rendered incapacitated spectators tends to foreclose any analysis of the multiplicities and contradictions in capitalist development on the one hand, and the possibilities of resistance in everyday practice (beyond radical revolutionary change) on the other. ${ }^{3}$ Another problem arises from the tendency of academic scholars to label the work of Debord and the SI as artistic practices with a focus on aesthetics and visual elements, an assumption that sets them apart from the supposedly more authoritative, empirical social scientific studies of consumption and social change (Gotham and Krier, p.158). While many techniques of the SI, such as derive (meaning 'drift'), a 'dialectic wandering' in the city that enables new discoveries, and detournment, which appropriates expressions of the capitalist system and turns them against the latter, have been enthusiastically embraced by those working in the creative fields including architecture, urban design and contemporary art, these techniques are sometimes deemed to have become the tools of capital, coopted by powerful corporations eager to deploy innovative strategies for generating ever more authentic consumer experience in the ongoing quest to expand the market (Krupar and Al, p.256). ${ }^{4}$ This ironic situation is captured by Jacques Ranciere's contention that detournment has become such a standardized practice that it no longer detournes anything very much any more (Ranciere, 2009, p. 76; Cunningham, 2013, p.57).

\footnotetext{
${ }^{1}$ Situationist International (SI) was formed in 1957 with Guy Debord as one of its founding members. The group includes artists, architects, activists and political theorists that were committed to the ${ }^{2}$ Pinder notes that interest in Debord's work come from different disciplines, most prominently in contemporary critical theory and cultural studies focusing on electronic media, new forms of consumption, and notions of a 'postmodern' age or condition, In addition, it has also been featured in critical discussion of vision and visuality in relation to histories of Western Marxism. (Pinder, p.361).

${ }^{3}$ Also see comments by Gotham and Krier.

${ }^{4}$ For an explanation of SI's tactics, see Macdonald.
} 
Do these realizations imply then, that the spectacle concept is simply a theoretical dead end? While this is not the place to trace its career through the writings of different theorists since Debord, it is useful to refer to Mitchell's comment that whether or not one agrees that the spectacle represents a 'totalizing closure,' it must be acknowledged that no amount of critique will make the word and the lure of its imaginaries disappear any time soon (Mitchell, p.577). Rather than dismissing it as an outmoded concept or sinister avatar of capital needing to be continuously attacked, Mitchell asks why not approach the spectacle as a contested terrain on which micro-political struggles continue to run up against dominant economic and cultural discourses? What seems more urgently needed, perhaps, is a better grasp of how different forms of the spectacle operate in specific geopolitical spaces and engender particular contradictions, resistance and co-options, as well as new knowledge and aspirations that are themselves contingent upon historic experiences and wider economic and political change.

It is worth noting here that in Debord's formulation, the spectacle is not visual at its core, as often assumed, but a social relationship between people that is mediated by images (Debord, 1967). ${ }^{5}$ Although the fetishistic images of the spectacle conceal the domination and exploitative conditions of the capitalist system, they also define the conditions of possibility for change and resistance to it. Debord has also differentiated between three kinds of spectacles: the 'concentrated,' found in bureaucratic societies under authoritarian regimes; the 'diffused,' found in developed capitalist societies with abundance of commodities; and the 'integrated,' which refers to the eventual triumph of the latter over the former in contemporary neoliberal globalization (Debord, 1988; Campbell, p.545). ${ }^{6}$ While the division of these categories may appear mechanistic, they nevertheless provide grounds for us to consider more carefully how the spectacle travels the line from the concentrated to the integrated in different geopolitical contexts, and by doing so elucidates the convergence and divergence of ideologies, narratives, and political strategies in ongoing capitalist development. $^{7}$

To do this one certainly cannot assume a dichotomy between 'image' and 'reality,' predicated on the belief that there is something more 'real' and 'concrete' hidden underneath the illusive

\footnotetext{
${ }^{5}$ Also see G.Leung, The Sociality of the Spectacle (2010).

${ }^{6}$ Campbell notes that the victory of the integrated spectacle results in two things. "The first involves a series of characteristics described by Debord as 'incessant technological renewal; integration of state and economy; generalized secrecy; unanswerable lies; and eternal present.' The second is the cultural product of these five characteristics: the eradication of historical knowledge such that "contemporary events themselves retreat into a remote and fabulous realm of unverifiable stories, un-checkable statistics, unlikely explanations and untenable reasoning." (Campbell 2008, p.545).

${ }^{7} \mathrm{See}$, for example, Campbell's analysis of the society par excellence in Milosovic's Yugoslavia (Campbell, 2008).
} 
façades of the spectacle. This is because it is precisely via the latter - the material forms of contemporary capitalism -- that we come to acquire our present sense of perception and actual relations to the world (Cunningham, 2013, p.39). And indeed, as noted in David Cunningham's reference to Benjamin, if humanity's mode of perception changes in different periods in ways that are not conditioned by nature but by history, then the development of the contemporary metropolis, which is increasingly shaped by new kinds of spectacular spaces, objects and images, must be seen as the very means for the continual transformation of our sense of perception, and hence 'the mode of existence of human collectives.' (Cunningham, p.39; Crary, p.98).

Although scholars of urban studies have historically paid limited attention to Debord's insight on the dialectic of the spectacle in their analysis of contemporary urbanism, it is worth noting its significant influence on Henri Lefebvre, whose formulation of the production of space is now a standard text for urban analysis (Lefebvre 1991; Pinder, 2000; Swyngedouw, 2002). Closely related to Debord's dialectic is Lefebvre's notions of abstract space, which refers to the homogeneous space produced by capitalist exchange, and differentiated space, which arises from the internal contradictions of the former and embraces difference (Lefebvre; Pinder, p.363). Both Debord and Lefebvre shared the belief that capitalism can never be reduced to pure logics of capital accumulation, and that the modern metropolis is not only an arena of domination but also of contestation and political struggles that always carries the potentials for revolutionary change.

Debord's concerns of the possibilities of counter practices in transforming society have not been lost amongst those studying communication and visual culture, who tend to assume a more nuanced and even hopeful stance towards urban change. Certainly this has to do with the growing prominence of communication technologies and concomitant democratization of images, which make it easier to 'hijack' the spectacle apparatus via the media and other creative practices (Leung, 2010). An example of recent efforts to recuperate Debord's dialectic can be seen in the book Spectacle Pedagogy by Charles Garoian and Yvonne Gaudelius (2008). The authors posit that critical engagement with the spectacle in visual and performance art is crucial for revealing its inherent contradictions, allowing performers and audience to produce alternative imaginaries and new knowledge required for political interventions. The potentials of subversive political acts have also been explored in a recent issue in the journal Invisible Culture entitled 'Spectacle East Asia' (2010). Here, contributors examine how social actors employ various tactics to hijack spectacular events in order to encourage civil disobedience and public debates on development projects and political and social issues, thus illustrating the productive nature of the spectacle and its embedded 
‘alternative modes of sociality' (Leung, 2010).

While these examples demonstrate the possibility of resistance to particular projects and political agendas, it remains unclear to what extent these practices and alternative pedagogical approaches can bring about more lasting changes to our existing mode of capitalist relations. After all, as mentioned earlier, many forms of 'counter-practices' inspired by the SI have too quickly been coopted as part of neoliberal corporate strategies for further commodification of the environment and ongoing calibration of consumerist subjectivities. If the spectacle indeed defines the conditions of possibility for change and resistance, then perhaps more work is required to elucidate how it functions as a 'governing arrangement,' which involves different components that regulate our everyday social relations and organize urban knowledge (Krupar, 2012). This also suggests, to follow Allen Pred, that we need to explore the 'social fact-ness' of the spectacle; that as a technology of power and as pedagogy, how it comes to achieve legitimacy through popular consent rather than through coercion (ala Foucault), and to inculcate a particular way of seeing the world and reorganize the power relations among the state, the economy and culture (Pred, 1995; Krupar, 2012).

It is in with these questions in mind that this special issue focuses on the productive nature of the spectacle. By using spectacular urbanism as a lens, each paper considers how particular kinds of aesthetics, imaginaries and knowledges are mobilized in the ongoing production of urban space in contemporary cities and how the latter give shape to new social relations and aspirations. We posit that a reconsideration of the spectacle dialectic as conceived by Debord is especially timely given the growing importance of the image and ascendance of the experience economy in contemporary capitalist globalization. These developments have also accorded a new significance of the 'urban' across disciplines in the humanities and social sciences, which saw the emergence of new conceptual key terms such as worlding, networks, and assemblages -- concepts that invariably seek to explain the complex exchange of ideas, images and practices that play increasing roles in the reformation of cities and urban milieus. These observations further suggest an urgent need for more trans-disciplinary enquiries that are able to connect different domains of knowledge. To this end, the theme of 'spectacle cities' can offer access to distinctive features of contemporary urban processes and help form new theoretical frames and conjunctures.

The articles brought together in the issue examine different aspects of the spectacle and represent a diversity of methodological lenses. Kah Wee Lee's paper, for example, explores the role of affect in the production of spectacular urban spaces and how they are inseparable from each other. By focusing on a new shopping mall cum residential tower, ION Orchard in 
Singapore, Lee explores the dense network of politics and practices through which experts and institutions frame, instrumentalize and act on the problem-space of affect. While the experts involved such as architects and planners might all recognize the growing role of providing a 'mutli-sensory experience' for consumers, their perceived values of affect and points of intervention are not consistent, such that the work of one group of experts can be negated, undermined or ignored by the work of another. Importantly, his article highlights the competing regimes of values, interests and techniques that converge but do not map neatly onto each other.

Max Woodworth continues with the discussion of the contradictory nature of the spectacle by exploring the role of oppositional practices played out in urban space. Here, he examines the work of contemporary Chinese artist Zhang Dali's graffiti project in an effort to shift attention from the spectacular nature of Beijing's recent architectural history to the 'peculiar insurgent urban practice in the city's ubiquitous spaces of ruin and redevelopment.' Woodworth argues that by paying attention to how the art and artist navigated this fraught landscape and the different ways in which people contest its meanings, it is possible to engage with a critical approach to urban spectacles by seeing them as existing on a contested terrain rather than as being part of a one-sided capitalist juggernaut. Furthermore, this exploration illuminates how China's state-led urbanization is being continually unsettled by countervailing and disruptive social forces.

Alessandro Angelini's paper provides a genealogy of the spectacle beyond the modern North Atlantic metropole and an examination of the origin myth of the favela within the Brazilian geographical imagination. More specifically, the paper focuses on a role-playing game hosted in Morrinho, a miniature world built by a favela youth collective in Rio that is built of bricks, mortar, and re-used materials and featured thousands of inch-tall avatars. Angelini's analysis, which is supported by years of ethnographic study and participant observation, offers a possibility to study alterity in the margins of Rio. Arguing that all visual signs have social lives of their own, Angelini suggests that play, as a mode of representing and engaging with the world, becomes a basis for alternative ways of knowing the city. Like Woodworth, Angelini's paper offers an approach to shift conversations about mega-event urbanization and regeneration schemes towards a methodology that focuses on specific histories and cultural forces. His paper reminds us that 'Debord's concept of the spectacle drew its power and popularity from its capacity to explain seemingly everything about how capitalism captures and shapes collective desires and fears, but this very ominpotence was also its limitation.' 
Romola Sanyal and Gareth Jones's paper examines the slum as spectacle and how the knowledge of it is produced through slum tours, art and television. In particular, their work focuses on Dharavi, India's largest and most well-known slum. They draw together the literatures on spectacle and worlding and consider how the making of the slum as spectacle is also a way to 'world' Dharavi. In other words, these tours and other media productions of Dharavi produce a particular narrative about the slum that writes against the elite and hegemonic imaginations of Mumbai as a world-class city. Here poverty and resilience is valorized and used as lessons and points of reflection for a largely western audience. Dharavi enters the world through the tour, artwork and television and a certain idea of it gets circulated globally. Thus even as Dharavi's counter-narrative to Mumbai's ambitious redevelopment plans is disruptive, simultaneously, its own image becomes centered. The authors consider what this means ultimately in terms of producing politics of solidarity.

Finally, Cecilia Chu's paper examines the tensions and conflicts generated by Macau's spectacular transformation in recent years via the construction of two incongruent landscapes: a fantasyland of gaming and a 'historic city of culture.' Building on Debord's conception of the dialectic of the spectacle, Chu illustrates how the growing support for heritage conservation in postcolonial Macau has been propelled by a shared anxiety over the phenomenal changes brought by an expanding casino industry and concomitant erosion of Macau's cultural identity. Through extensive interviews with architects, conservation experts and local activists, she elucidates how the inscription of Macau as a UNESCO World Heritage City has helped consolidate particular sets of moral claims around heritage and gaming and helped galvanize new imaginaries amongst Macau's residents. Although the enactment of Macau as a World Heritage City has offered new hopes for preserving its 'local culture,' it also introduces new commodifications of the environment that cannot be easily delinked from other spaces of the 'spectacle city.'

Taken together, the papers of this special issue contribute to a better understanding of the dialectical and productive nature of urban spectacles and their roles in the ongoing production of social relations and aspirations. By exploring the complexities and contradictions entailed in spectacle-making processes and the concomitant possibilities for re-experiencing and rescripting the urban environments in different geopolitical contexts, the collection illustrates the necessity of attending to linkages between local practices and emergent discourses of neoliberal urban reform. The papers further underscore the need for more trans-disciplinary and transnational enquiry that enables a better grasp of the continuities and discontinuities of urban processes and the ongoing reshaping of the urban milieu under accelerating capitalist globalization. 


\section{References}

Barnard, A., 2004. The legacy of the Situationist International: The production of situations of creative resistance. Capital \& Class 84, 103-124.

Best, S. and Kellner, D., 1999. Debord and the postmodern turn: New stages of the spectacle. Substance 90, 129-156.

Brenkman, J., 1979. Mass media: From collective experience to the culture of privatization. Social Text 1, 94-109.

Campbell, D., 2008. Beyond image and reality: critique and resistance in the age of spectacle. Public Culture 20 (3), 539-549.

Crary, J., 1989. Spectacle, attention, counter-memory. October 50, 96-107.

Cunningham, D., 2013. Floating on the same plane: metropolis, money and the culture of abstraction. Journal of Visual Culture 12 (1), 38-60.

Debord, G., 1995 (1967). Society of the spectacle. Zone Books.

Debord, G., 1990 (1988). Comments on the society of the spectacle. Verso.

Foster, R.J., 2008. Commodities, brands, love and kula: Comparative notes on value creation in honor of Nancy Munn. Anthropological Theory 8 (1), 9-25.

Garoian, C.R., and Gaudelius, Y. M., 2008. Spectacle pedagogy: Art, politics, and visual culture. State University of New York Press.

Gotham, K.F., and Krier, D.A., 2008. From the culture industry to the society of the spectacle: Critical theory and the Situationist International. Current Perspectives in Social Theory 25, 155-192.

Gotham, K.F., 2005. Theorizing urban spectacles: Festivals, tourism and the transformation of urban space. City 9 (2), 225-246.

Jappe, A., 1999. Guy Debord. University of California Press.

Klingmann, A., 2007. Brandscapes: Architecture in the experience economy. The MIT Press.

Krupar, S., 2014. The political materialism of spectacle: A cross-sectional examination of the edaphological geopolitiecs of the Shanghai 2010 World Expo. In: Geographies of power: Re-cognizing the present moment of danger, edited by H. Merrill and L. Hoffman. University of Georgia Press.

Krupar, S., and Al, Stefan., 2012. Notes on the society of the spectacle brand. In: The SAGE Handbook of Architectural Theory, edited by C.G. Crysler, S. Cairns and H. Heynen. SAGE Publications, 247-274.

Leung, G., 2010. Introduction: The sociality of the spectacle. Invisible Culture 15, 1-11.

Ley, D., and Olds, K., 1988. Landscape as spectacle: World's fairs and the culture of heroic consumption. Environment and Planning D: Society and Space 6, 191-212.

Macdonald, B.J., 1995. From the spectacle to unitary urbanism: Reassessing Situationist 
theory. Rethinking Marxism 8 (2), 89-111.

Mitchell, W.J.T. 2008. The spectacle today: A response to RETORT. Public Culture 20 (3), 573-581.

Ong, A., 2012. Introduction: Worlding cities, or the art of being global. In: Worlding Cities: Asian experiments and the art of being global, edited by A. Roy and A. Ong. Wileyblackwell, 1-26.

Pinder, D., 2000. 'Old Paris is no more': Geographies of spectacle and anti-spectacle. Antipode 32 (4), 357-386.

Pred, A.R., 1995. Recognizing European modernities: A montage of the present. Routledge. Ranciere, J., 2009. The emancipated spectator. Verso.

Stevens, Q. and Dovey, K., 2004. Appropriating the spectacle: Play and politics in a leisure landscape. Journal of Urban Design 9 (3), 351-365.

Swyngedouw, E., 2002. 'The strange respectability of the Situationist city in the society of the spectacle.' International Journal of Urban and Regional Research, 26 (1), 153-65. 